Quito, 31 de julio, 1 ro de agosto 2006 - Santa Cruz, Galápagos, 3-4 de agosto 2006

\title{
Coloquio Científico Internacional Galápagos Ciencias Sociales para una Sociedad Sostenible
} Quito, 31 de julio, 1ro de agosto 2006 - Santa Cruz, Galápagos, 3-4 de agosto 2006

\section{Christophe Grenier y Pablo Ospina}

\section{(2) OpenEdition Journals \\ Edición electrónica \\ URL: http://journals.openedition.org/bifea/4703 \\ DOI: $10.4000 /$ bifea. 4703 \\ ISSN: 2076-5827 \\ Editor \\ Institut Français d'Études Andines}

\section{Edición impresa}

Fecha de publicación: 1 mayo 2006

Paginación: 230-231

ISSN: 0303-7495

\section{Referencia electrónica}

Christophe Grenier y Pablo Ospina, « Coloquio Científico Internacional Galápagos Ciencias Sociales para una Sociedad Sostenible », Bulletin de l'Institut français d'études andines [En línea], 35 (2) | 2006, Publicado el 08 mayo 2006, consultado el 01 diciembre 2020. URL : http://journals.openedition.org/ bifea/4703 ; DOI : https://doi.org/10.4000/bifea.4703

\section{(c) (i) $\odot$}

Les contenus du Bulletin de l'Institut français d'études andines sont mis à disposition selon les termes de la licence Creative Commons Attribution - Pas d'Utilisation Commerciale - Pas de Modification 4.0 International. 


\section{COLOQUIO CIENTÍFICO INTERNACIONAL GALÁPAGOS CIENCIAS SOCIALES PARA UNA}

\section{SOCIEDAD SOSTENIBLE}

Quito, 31 de julio, 1 ro de agosto 2006 - Santa Cruz, Galápagos, 3-4 de agosto 2006

EL «Coloquio científico internacional Galápagos ciencias sociales para una sociedad sostenible» se llevó a cabo en la Universidad Andina Simon Bolívar en Quito los días 31 de julio y $1^{\text {ro }}$ de agosto; luego en el Municipio de Santa Cruz en las islas Galápagos el 3 y 4 de agosto de 2006: se trataba del mismo coloquio; es decir que las comunicaciones han sido presentadas dos veces.

Se presentaron en Quito 35 comunicaciones. El nivel académico de las comunicaciones ha sido muy variado, sin embargo el conjunto resultó de buen nivel. Las actas del coloquio deberían ser publicadas en Quito a más tardar a fines de 2006. 
Se hicieron varios planteamientos prácticos:

- completar la «línea base», el «estado del arte» de las ciencias sociales en Galápagos.

- el coloquio no debe ser sólo de ciencias sociales, sino un «Foro de las ciencias en Galápagos».

- es necesario avanzar en una estrategia y política de ciencias y tecnologías en Galápagos.

Se hicieron también planteamientos debatidos en el Coloquio sobre las prioridades de conocimiento social:

1. Es necesario partir de la información que existe.

2. La investigación social es útil para conocernos más a nosotros mismos así como para conocer y tratar de respetar a los otros.

3. La investigación social puede servir también para hacernos mejores y más profundas preguntas sobre la realidad y sobre los escenarios futuros.

Se debatieron sobre enfoques conceptuales y perspectivas teóricas que hacen falta desarrollar como marco general de las investigaciones sobre la sociedad galapagueña (enfocarse en las relaciones entre los fenómenos y las cosas que atañen al conjunto de la sociedad, antes que en sus efectos parciales o aislados; avanzar conceptualmente y prácticamente en enfoques y trabajos interdisciplinarios que vinculen las ciencias biofísicas, ecológicas y humanas; estudiar mucho más en términos comparativos las realidades, problemas y soluciones en Galápagos).

Se trataron varios temas y preguntas específicas:

- El primer gran tema trató de saber si el proceso de crecimiento económico que vive Galápagos está o no en contradicción irresoluble con la sustentabilidad.

- El segundo gran tema mencionado insistentemente es el que tiene que ver con las formas de gobierno, toma de decisiones políticas y ejercicio de los liderazgos en las islas.

- El tercer tema de importancia crucial justamente vinculado a la toma de decisiones y a los conflictos sociales existentes es el de la "cultura".

- El cuarto tema fue el del manejo del turismo por sus impactos tanto en el crecimiento económico como en la gobernabilidad.

Se debatieron sobre los mecanismos para el diálogo y la promoción de investigaciones (necesidad de mejorar el acceso a la información por parte de la población interesada; constituir un pequeño fondo de becas para tesis de estudiantes universitarios y de posgrado tanto del país como de Galápagos o convocar periódicamente a un concurso de investigación con algunas de las preguntas prioritarias mencionadas en este documento; promover mecanismos de debate social, de difusión de los resultados de las investigaciones existentes y futuras).

A pesar de sus fallas, este coloquio es un evento importante en la medida que es el primero en ciencias sociales que se lleva a cabo en las Galápagos, cuando los eventos en ciencias naturales sobre el mismo tema ya son innumerables. Ahora bien, siendo estas islas un símbolo de la conservación de la naturaleza, lo que estaba en juego con esta reunión era muy importante: se trataba de hacer tomar conciencia a los responsables implicados en el tema que la conservación de la naturaleza es, en primer lugar, una cuestión social. 